\title{
Expert's opinion of a home-based exercise program for shoulder pain prevention: application in wheelchair basketball players.
}

\author{
Saleky GARCÍA-GÓMEZ ${ }^{1}$, Javier PÉREZ -TEJERO ${ }^{1}$, \\ Carmen OCETE ${ }^{1}$, Rubén BARAKAT ${ }^{2}$ \\ ${ }^{1}$ Cathedra Sanitas Foundation of Inclusive Sport Studies. Faculty of Physical Activity and Sports \\ Sciences, Technical University of Madrid \\ ${ }^{2}$ AFIPE research group. Technical University of Madrid \\ mailto:j.perez@upm.es
}

(Received on February 3, 2001; Accepted on May 5, 2017)

\begin{abstract}
The aim of the study was to assess the structure and content validity of a home-based exercise program, as an instrument to prevent of shoulder pain (SP) in wheelchair basketball players. The proposed program was designed considering previous studies but to be applied in this specific population and; it was composed by exercises based on active mobility ( 4 exercises), strengthening ( 5 exercises) and stretching (5 exercises) of the shoulder joint. An ad hoc questionnaire was administered to a convenience sample of 9 experts ( 1 rehabilitation physician, 1 sport physician, 4 physiotherapists and 3 coaches) that fulfilled the defined inclusion criteria. The results showed that experts considered the shoulder home-based exercise program (SHEP) as adequate tool for SP prevention in WB; however, some experts suggested some changes to improve it. According to the qualitative analysis performed, findings revealed two main underlying factors such as "design" (content and structure) and "application" that could influence in the adequate use of the home-based exercise program. This study provided evidence that the presented home-based exercise program is a validate tool and could be a powerful tool to prevent shoulder pain in WB player's population.
\end{abstract}

Keywords: Adapted sport, shoulder injury, wheelchair users, evaluation.

Opinión de expertos sobre un programa de ejercicio realizado en casa para la prevención de dolor de hombro: aplicación en jugadores de baloncesto en silla de ruedas.

RESUMEN: El objetivo de este estudio fue evaluar la estructura y validez del contenido de un programa de ejercicios realizados en casa, como instrumento para prevenir el dolor de hombro en jugadores de baloncesto en silla de ruedas. El programa propuesto se diseñó teniendo en cuenta estudios previos a los fines de aplicar el programa de ejercicio en esta población; se compone de ejercicios basados en movilidad activa (4 ejercicios), fortalecimiento (5 ejercicios) y estiramientos $(5$ ejercicios) de la articulación del hombro. Se administró un cuestionario ad hoc a 9 expertos (1 médico rehabilitador, 1 médico deportivo, 4 fisioterapeutas y 3 entrenadores) que cumplieron con los criterios de inclusión definidos. De acuerdo a los resultados, los expertos consideran el programa de ejercicios realizados en casa (SHEP, siglas en inglés) como una herramienta adecuada para la prevención del SP en el WB. Sin embargo, algunos expertos sugirieron algunos cambios para mejorarlo. En cuanto al 
análisis cualitativo realizado, los hallazgos revelaron dos factores subyacentes principales tales como "diseño" (contenido y estructura) y "aplicación" que podrían influir en el uso adecuado del programa de ejercicios en el hogar. Este estudio proporcionó evidencias sobre la efectividad del programa de ejercicios realizado en casa como una herramienta válida para prevenir el dolor en el hombro en la población de jugadores de baloncesto en silla de ruedas.

Palabras clave: Deporte adaptado, lesiones del hombro, usuarios silla de ruedas, evaluación.

Correspondencia: Javier Pérez Tejero. Cathedra Sanitas Foundation of Studies Inclusive Sport. Faculty of Physical Activity and Sports Sciences, Technical University of Madrid, Madrid, Spain. Martín Fierro, 7, s/n 28040, Madrid, Spain. 9133641 40. Email: j.perez@upm.es.

\section{Introduction}

Degenerative joint disease of the shoulder appears as a significant source of soft tissue injuries in general population (Killian, Cavinatto, Galatz, \& Thomopoulos, 2012). Studies suggest that exercise is an important tool as an element to treat and prevent shoulder pain (SP) as a result of injuries (Nawoczenski, Ritter-Soronen, Wilson, Howe, \& Ludewig, 2006; Van Straaten, Cloud, Morrow, Ludewig, \& Zhao, 2014) in wheelchair users. In this regard, some studies documented the influence of an home-based exercise program on shoulder injuries in wheelchair users (Curtis, Tyner, Zachary, Lentell, Brink, D., Didyk, T. et al., 1999; Mulroy, Thompson, Kemp, Hatchett, Newsam, Lupold, et al., 2011; Nash, van de Ven, van Elk, \& Johnson, 2007; Jacobs, Mahoney, Nash, \& Green, 2002), pointing out its benefits for shoulder health in this population. Furthermore, it has been shown that the results of these programs suggest that posterior shoulder muscles strengthening (to provide shoulder stability) and stretching (to promote the mobility of the shoulder) are fundamental training contents in these programs, in order to prevent postural changes related with muscular imbalance. For those reasons, an intervention program would be a useful for prevent SP in WB players.

Most of the previous studies report shoulder injuries as a main problem in this population (Samuelsson, Tropp, \& Gerdle, 2004; Wessels, Brown, Ebersole, \& Sosnoff, 2013), being SP one of the most common symptoms of physical dysfunction, mainly as a consequence of the increased load at this joint and repetitive stress of daily and sport activities (Fullerton et al., 2003; Nyland, Robinson, Caborn, Knapp, \& Brosky, 1997). About 70\% of wheelchair user's population has experienced SP in some moment of their life (Curtis, Roach, Applegate, Amar, Benbow, Genecco, et al., 1995). Precautions to prevent overuse injuries of the shoulders must be taken for those who do upper extremity exercise (Jacobs \& Nash, 2004; Burnham, May, Nelson, Steadward, \& Reid, 1993).

In this regard, wheelchair athletes sustain injuries that are related to the demands of their specific sports (Curtis, 1997), for instance, in wheelchair basketball (WB), probably the most popular adapted sport practiced (Crespo-Ruíz, Del Ama-Espinosa, \& Gil-Agudo, 2011). However, to the authors' knowledge, no studies of a home-based exercise program to prevent SP have been implemented in WB players. These players train for many hours over a long period (Curtis \& Dillon, 1985, Curtis et al., 1995); moreover specific movements implicated in this sport, such as pushing wheelchair and overhead for shooting, do rebounds and long passes; also, players with age less than 30 years reported SP when performing specific WB situation (c) Psy, Soc, \& Educ, 2017, Vol. 9(3) 
during competition. (García-Gómez \& Pérez-Tejero, 2017). In addition, SP affect more activities of daily living (ADLs) than sport activities in WB players related to age, years of wheelchair use; however SP related to sport activities had more SP do rebounding/one-handed long passes according to wheelchair use (García-Gómez \& Pérez-Tejero, 2016).

Both novice and elite WB players experience soft tissue injuries to the upper extremity specifically in wheelchair basketball (Curtis, 1997; Curtis et al., 1995). In contrast, other study specifies that older males have a higher risk of SP (Tsunoda, Mutsuzaki, Hotta, Tachibana, Shimizu, et al., 2016).

To the authors' knowledge, it is unknown the impact to a shoulder home-based exercise program (SHEP) in this specific population. In this regard, it seems relevant to design, to validate and to apply a SHEP to facilitate own administration in WB players. For all of the above mentioned, the aim of the study was to assess the structure and content validity of a SHEP prevention in WB players.

\section{Method}

\section{Participants}

To assess the validity of a SHEP, 14 possible candidates to participate as expert in this study were identified: 9 participants (including 1 rehabilitation physician, 1 sport physician, 4 physiotherapists and 3 coaches, (Insert here Figure 1). The inclusion criteria for the experts were to (1) be a physiotherapist with minimal of five years of experience in WB high level competition (2) be a coach or physical trainer with minimal experience of five years in WB high level competition and (3) be a physician with experience in WB high competition.

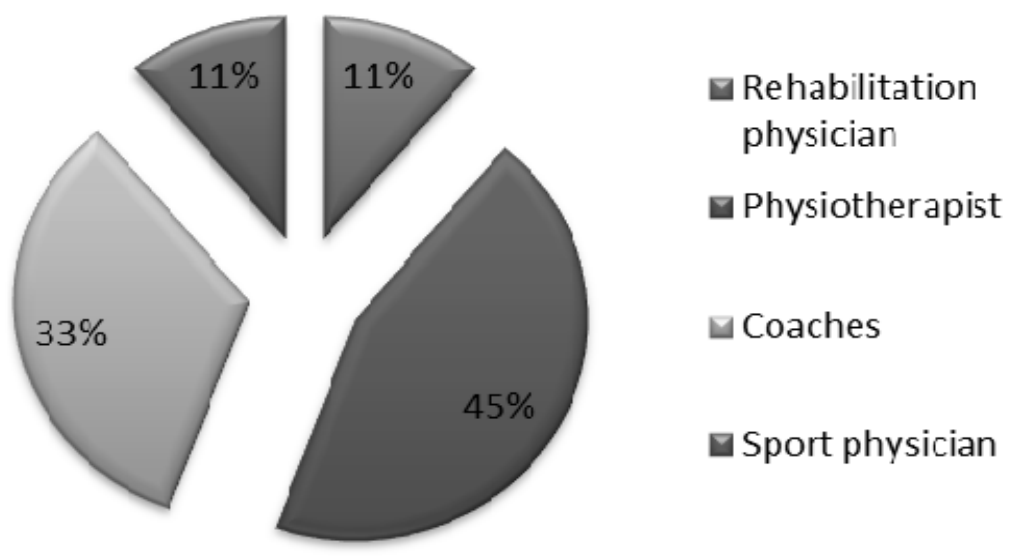

Figure 1. Experts Occupation.

All participants were contacted and recruited through e-mail by a member of the team research. All of them provided written consent for participation in the study, and information regarding 
demographics data and WB experience was obtained. The present study is part of a nonrandomized clinical trial (NCT02842008). The protocol for this study was approved by the ethical committee of the Technical University of Madrid.

\section{Design}

Three phases were established to design, apply and assess the relevance of the proposed SHEP in WB players (Figure 2).

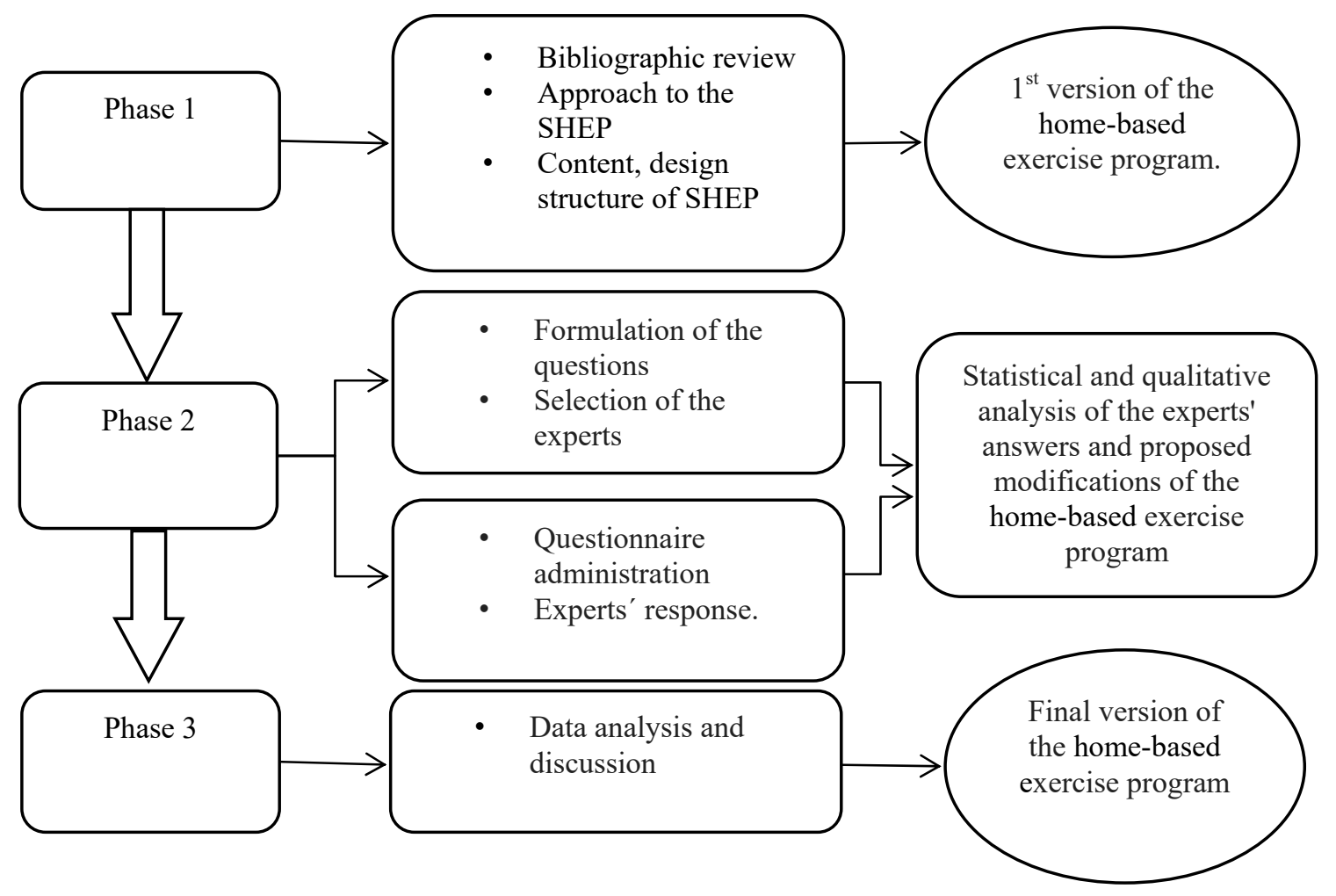

Figure 2. Research Design.

\section{Exercise program for shoulder pain prevention in WB players}

The SHEP it is composed by different exercises based on active mobility, strengthening and stretching to be administered 3 times per week (Insert here Table 1). This exercise program was based in previous studies (Curtis et al., 1999; Mulroy, Thompson, Kemp, Hatchett, Newsam, Lupold et al., 2011; Nawoczenski, Ritter-Soronen, Wilson, Howe, \& Ludewig, 2006; Van Straaten, Cloud, Morrow, Ludewig, \& Zhao, 2014) assessing the effect of exercise on shoulder pain an how affects function. 
Table 1. The proposed home-based exercise program for shoulder pain prevention in WB players

\begin{tabular}{|c|c|c|}
\hline Exercise & Specific movements & Frequency \\
\hline Active Mobility & $\begin{array}{l}\text { 1. Flexion. } \\
\text { 2. Circular movements of the shoulder. } \\
\text { 3. Adduction. } \\
\text { 4. With arms separated from the body } \\
\text { making movements carrying the arms forward } \\
\text { and backward. }\end{array}$ & $\begin{array}{l}8 \text { repetitions for each } 4 \\
\text { different movements. } \\
\text { Rest period: } 45 \text { seconds. }\end{array}$ \\
\hline $\begin{array}{l}\text { Strengthening } \\
\text { (resistive bands) }\end{array}$ & $\begin{array}{ll}\text { 1. } & \text { Serratus anterior. } \\
\text { 2. } & \text { Scapular retractors and depressor. } \\
\text { 3. } & \text { Shoulder external rotation. } \\
\text { 4. } & \text { Shoulder internal rotation. } \\
\text { 5. } & \text { Shoulder adduction. } \\
\end{array}$ & $\begin{array}{l}3 \text { sets of } 10 \text { repetitions for } \\
\text { each movement. } \\
\text { Rest period: } 45 \text { seconds. }\end{array}$ \\
\hline Stretching & $\begin{array}{ll}\text { 1. } & \text { Trapezius upper portion. } \\
\text { 2. } & \text { Posterior shoulder. } \\
\text { 3. } & \text { Pectoral stretch. } \\
\text { 4. } & \text { Brachial biceps stretch. } \\
\text { 5. } & \text { Trapezius lower portion. } \\
\end{array}$ & $\begin{array}{l}5 \text { repetitions for each } 5 \\
\text { proposed exercises. } \\
\text { Rest: } 30 \text { seconds rest. }\end{array}$ \\
\hline
\end{tabular}

\section{Instrument}

A questionnaire was designed ad hoc composed by nine questions, being:

1. Three questions related to demographic data, workplace and professional relation with WB.

2. Five open questions related to SHEP: utility, content, necessity of the program, other opinions and aspects to be improved.

3. Fourteen affirmations to be assessed by a Likert scale of six possibilities (from 0 to 5 , its means from totally disagree to totally agree) related with different aspects of the proposed home exercise program. Affirmations were related with the following topics (adapted from Yoo, Hwang, Lee, \& Kim, 2003): clear and well defined objective, content organized per objective, the program is perceived as an important therapeutic tool, scientific bases, contains sufficient quantity and quality of information, current, contrasted and updated information, logical structure, clear and simple explanation, efficiently detailed structure, appropriate for therapeutic approach and relationship exercise, useful in relation to the object of study and its real applicability, easily reproducible, sequence of appropriate exercises and number of repetitions and adequate rest time.

Questionnaire provision to the experts was strictly confidential and communication between experts was not promoted along its administration neither after the study.

\section{Procedure}

Firstly, all experts were informed of the purpose and methodology of the study, and, after their participation confirmation, the designed questionnaire was sent to each expert trough personal email, including a link to an online website where the questionnaire was fulfilled and data were 
stored. In this regard, experts were request to provide their feedback on the SHEP including general and specific characteristics of the program.

\section{Data Analysis}

\section{Qualitative Analysis}

The observations, comments and opinions provided were systematically collected regarding the professional occupation of the experts. After data collection, qualitative analysis was performed following Heinemann (2003) proposed methodology: in a first phase, intensive floating reading was used in order to create a general outline of the content, topics and arguments. In a second phase, prior to analysis, data codification and categorization was performed using NVivo 18.0 program, and major results, topics and arguments where structured by experts' profession. According to the codification of the experts, it was specified the professional occupations of each expert, we will refer the physiotherapist, as "PH", coaches as "CH", rehabilitation physician as "RP" and sport physician as "SP; with a number, for example, for the physiotherapist, expert number one the codification was "PH1".

\section{Statistical analysis}

For statistical analysis, demographic data were analyzed using descriptive statistics. SPSS V18.0 program was used for the data analysis.

\section{RESULTS}

\section{Qualitative analysis}

According to the data analysis, there is a major trend of the answers regarding the design of the program with 53 content units, focused mainly on the content (40 units of contents) and structure (13 units of contents) of the program and its application, with 30 content units. The analysis of the answers of the experts it has been made per professional occupation.

The demographic characteristics of the experts showed that the majority of the participants were men's (88\%) and the majority of participants per professional occupations were physiotherapists $(44 \%)$. According to the experts the proposed home-based exercise program with the adequate changes could be a useful tool in the context of the WB.

\section{Design of the shoulder home-based exercise program}

\section{Content of the shoulder home-based exercise program}

Related to the opinion of the physiotherapists they were more focused in aspects related to the content of the SHEP. Physiotherapists explained SHEP could include global movements and propioceptive exercises of the shoulder for example PH1 said "I think it would not be too much to include propioceptive exercises, not only for the shoulder". In this regard, $\mathrm{PH} 2$ consider that "an exercise prevention program should have more global movements than analytics 
movements" and "a propioceptive exercise program help to workout in general balancing tensions". In this regard, $\mathrm{PH} 2$ suggested "performing shoulder global movements and strengthening exercises using resistive and exercises for stabilization of the shoulder".

According to the physiotherapist main suggestion active movements in the first phase (PH2 "Active and dynamic stretching should be integrated prior to the completion of the strengthening program") of the home-based exercise program should be more extensive for example $\mathrm{PH} 2$ says "I consider that the section of active movements should be more extensive".

According to the content of the SHEP, one of the three coaches considers as a readaptation program not as a prevention exercise program; $\mathrm{CH} 3$ "seems a program of readaptation and not of prevention". In this regard, $\mathrm{CH} 2$ clarifies that the SHEP is "a battery of simple exercise that deals with its main aim" and $\mathrm{CH} 1$ explained "it would be necessary the creation of a prevention exercise program like this". Thus, $\mathrm{CH} 1$ considers that "there are gestures and actions that produce shoulder pain that could cause difficulties in the ADLs".

Also, there was a difference point of view of the coaches in order to include exercises that implicate increased joint range. $\mathrm{CH} 1$ considers "include a battery of exercises where the range of motion is as large as possible" while $\mathrm{CH} 3$ does not see it as a primary element to develop the SHEP "do not stretch passive-sustained in prevention exercises"; also, suggested "a differentiation in the typology of the exercises" in the section 3, referred to the strengthening exercises.

Related to the content, rehabilitation physician (RP1) consider "sometimes the redaction of the exercise seems a little bit complex" while sport physician (SP1) explain "they are simple and easy exercises". Both physicians consider SHEP a useful tool, for example RP1 said that "I find it useful because it offers in a systematic way and a complete approach of aspects such as active mobility, stretching and strengthening sections."

Structure of the shoulder home-based exercise program

All the experts concluded as an important element to include photographs or videos to explain the different SHEP exercises, as well as $\mathrm{PH} 1$ and $\mathrm{CH} 1$ suggested to change the sequence of the exercise (active mobility, strengthening, and strength); for example, $\mathrm{CH} 1$ consider that "the program should include active mobility before the realization of the strength exercises". In this regard, PH1 suggested the extension of the active mobility section. On other hand, SP1 suggested "to categorize the concrete times of the strengthening instead of generalizing between 20 and 30 seconds". SP1 consider adequate the structure of the SHEP "the exercises are perfectly described".

\section{Application of the home-based exercise program stretching}

In the context of this study, all the physiotherapists consider an exercise program as a useful tool for prevent SP (for example PH1: "everything that improve a better stability and flexibility of the shoulder it would be good for general population and much more for WB players"; PH2: "an exercise program always is useful to facilitate de activities of daily living such a transfers, 
etc."; PH3: "A good strengthening of the shoulder and that users are aware of the work they must do is always good for injury prevention"; PH4: "an exercise program work and prepare all the muscles involved in wheelchair propulsion since the shoulder complex suffer with ripped and braked". In contrast, PH 2 considers "there are players with a much more developed musculature and that is why I do not consider that a specific exercise program is the most necessary" understanding that "to include relax massages for long training process would be the most useful".

Related to the application of the SHEP, two physiotherapists considered it is necessary to take into account the functional classification of the players, since the lower points $(1.0-2.0$, those with higher physical impairment) could lose stability when they do the exercises with both arms simultaneously. Thus, $\mathrm{PH} 2$ explained "a player with low point could not be able to do active exercise with two arms at the same time because he/she could lose stability" and PH4 suggested to "divide exercises according higher and lower points". In addition, $\mathrm{PH} 2, \mathrm{PH} 3$ and PH4 consider fundamental the individualization of the exercise program to the player; PH3 explain that "exercise program should be individualized".

To the coaches' opinion, SHEP included the necessary exercises to prevent SP, for example $\mathrm{CH} 1$ explained that "All athletes should have an exercise program to prevent injuries, and especially those to prone to have chronic injuries". In this regard, $\mathrm{CH} 2$ considered "at the moment there is not an exercise program to develop in the wheelchair basketball training". Although, $\mathrm{CH} 2$ indicated that "exercise program's is not done in a systematic, continuous and consistent way in the context of the training sessions". On other hand, $\mathrm{CH} 3$ explained that players must do the exercise program "depending on the time of the season will be made more or less volume and intensity". Also, $\mathrm{CH} 1$ consider the individualization of the program "by adjusting the development of the exercise program to the specific case of each player".

Rehabilitation physician and sport physician explain the usefulness of the SHEP, RP1 explained "the approach is very complete and acceptable for the wheelchair basketball players"; in this line SP1 considered that exercise program "facilitates the strengthening of the main muscles of the shoulder, avoiding the appearance of the impingement syndrome".

\section{Quantitative analysis}

Regarding aspects related to the analysis of the SHEP, the average obtained from items related to clear and well defined objective, the scientific bases and appropriate for therapeutic approach of the program were higher than the rest of the aspects evaluated (Table 2). On the other hand, for the items related to the contains sufficient quantity and quality of information, sequence of appropriate exercise and logical structure, clear and simple explanation a lower average of the answers was obtained (Insert here Table 2). 
Table 2. Aspects related to the evaluation of the home-based exercise program

\begin{tabular}{lcc}
\hline & $\mathrm{X}$ & $\mathrm{XS}$ \\
\hline Clear and well defined objective. & 3.22 & 0.67 \\
Content organized per objective. & 3.11 & 1.26 \\
Perceived as an important therapeutic tool. & 3.22 & 0.97 \\
Based on scientific bases. & 3.67 & 1.00 \\
Contains sufficient quantity and quality of information. & 2.56 & 1.01 \\
Current, contrasted and updated information. & 3.11 & 0.78 \\
Logical structure, clear and simple explanation. & 2.56 & 1.33 \\
Efficiently detailed and detailed structure & 3.00 & 1.12 \\
Appropriate for therapeutic approach. & 3.33 & 0.71 \\
Appropriate relationship exercise & 2.78 & 0.97 \\
Useful in relation to the object of study and its real applicability. & 3.11 & 1.05 \\
Easily reproductible. & 3.11 & 1.05 \\
Sequence of appropriate exercise. & 2.44 & 1.42 \\
Number of repetitions and adequate rest time. & 3.22 & 0.67 \\
\hline
\end{tabular}

From 0 (totally disagree) to 5 (totally agree).

\section{Discussion}

The purpose of the current study was to assess the structure and content validity of the SHEP for the prevention of SP in WB according to the opinion of the experts group. The analysis of the data was based on qualitative and quantitative techniques per the design related to content and structure of the SHEP and their application.

Previous research (Nawoczenski, Ritter-Soronen, Wilson, Howe, \& Ludewig, 2006; Mulroy et al., 2011; Van Straaten, Cloud, Morrow, Ludewig, \& Zhao, 2014) indicated that home-based exercise program could optimize movement performance in ADLs. The SHEP was developed according to consistent previous studies (Curtis et al., 1999; Nawoczenski, Ritter-Soronen, Wilson, Howe, \& Ludewig, 2006; Van Straaten, Cloud, Morrow, Ludewig, \& Zhao, 2014; Mulroy, Thompson, Kemp, Hatchett, Newsam, Lupold, et al., 2011; Nash, van de Ven, van Elk, \& Johnson, 2007; Jacobs, Mahoney, Nash, \& Green, 2002). However, we contrasted the information of the literature with the experts who had relationship with WB players (Insert here Table 3). After expert's opinion analysis, all the changes were made to improve the instrument. 
Table 3. Qualitative aspects to improve per occupation profile related to Shoulder Prevention Exercise Program (SHEP) in contrast with literature

\begin{tabular}{|c|c|c|c|c|}
\hline \multirow{2}{*}{$\begin{array}{l}\text { Occupation } \\
\text { Profile }\end{array}$} & \multicolumn{2}{|c|}{ Design } & \multirow[t]{2}{*}{ Application } & \multirow{2}{*}{$\begin{array}{c}\text { SHEP elements according to } \\
\text { literature }\end{array}$} \\
\hline & Content & Structure & & \\
\hline Physiotherapist & $\begin{array}{l}\text {-Global } \\
\text { movements. } \\
\text {-Propioceptive } \\
\text { exercise. } \\
\text {-Active } \\
\text { mobility. } \\
\text {-Global } \\
\text { movements. } \\
\text {-Range of } \\
\text { motion. }\end{array}$ & $\begin{array}{l}\text { - Photographs } \\
\text { or video. } \\
\text {-Sequence of } \\
\text { exercise. } \\
\text {-Active } \\
\text { mobility before } \\
\text { strength. }\end{array}$ & $\begin{array}{l}\text {-Useful tool. } \\
\text {-Relax massages. } \\
\text {-Individualization } \\
\text { of the SHEP. }\end{array}$ & $\begin{array}{l}\text { Included } 3 \text { sessions: } \\
\text {-Active mobility (Mulroy et } \\
\text { al., 2011). } \\
\text {-Strengthening using resistive } \\
\text { bands (Curtis et al., 1999; } \\
\text { Nawoczenski et al., 2006; } \\
\text { Mulroy et al., 2011; Van } \\
\text { Straaten, et al., 2014) } \\
\text {-Strength (Curtis et al., 1999; } \\
\text { Nawoczenski et al., 2006; }\end{array}$ \\
\hline $\begin{array}{l}\text { Rehabilitation } \\
\text { Physician }\end{array}$ & $\begin{array}{l}\text {-Redaction of } \\
\text { the SHEP. }\end{array}$ & $\begin{array}{l}\text {-Photographs } \\
\text { or video. }\end{array}$ & -Useful tool. & Mulroy et al., 2011). \\
\hline Sport Physician & -Easy to use. & $\begin{array}{l}\text {-Specified time } \\
\text { of rest }\end{array}$ & -Useful tool. & $\begin{array}{l}\text { Specified the time of the } \\
\text { activity and rest (Curtis et al., } \\
\text { 1999; Mulroy et al., 2011) and } \\
\text { this program should be a } \\
\text { complement of training that } \\
\text { included photographs. }\end{array}$ \\
\hline
\end{tabular}

\section{Design of the shoulder home exercise program}

\section{Content of the shoulder home exercise program}

The result of the current study provides evidence that physiotherapist, rehabilitation physician and sport physician are more specific suggesting change in the aspects related to the design of the instrument specifically in the content. In this regard, related to the design of the program, the physiotherapist and coaches explained that the program in general is useful for WB players. However, they considered that SHEP could include global movements and propioceptive exercise of the shoulder. In this regard, the physiotherapist suggested to perform shoulder global movements as strengthening using resistive bands and stabilization of the shoulder. We include strengthening using resistive bands as previous studies (Mulroy, Thompson, Kemp, Hatchett, Newsam, Lupold, et al., 2011; Nash, van de Ven, van Elk, \& Johnson, 2007; Jacobs, Mahoney, Nash, \& Green, 2002; Nawoczenski, Ritter-Soronen, Wilson, Howe, \& Ludewig, 2006; Van Straaten, Cloud, Morrow, Ludewig, \& Zhao, 2014); however, exercise of stabilization was not included. The literature above mentioned has relationship with the descriptive data obtained that shows item related to base on scientific bases was higher than the others aspects evaluated.

\section{Structure of the shoulder home exercise program}

Other suggestion of the expert was to include photographs or video to explain the exercise program and consider the sequence of the exercise, this aspect had relationship with the quantitative analysis that shows a lower average in contrast with others. Per the physiotherapist (c) Psy, Soc, \& Educ, 2017, Vol. 9(3) 
and coaches, we needed to include more active mobility as a warm-up phase in the first phase of the exercise program. In this regard, literature supports the use (Mulroy et al., 2011) of this sequence (active mobility, strengthening, and strength).

\section{Application of the shoulder home exercise program}

Experts explained that the application of a shoulder home-based exercise program it is necessary for WB players, since shoulder injuries are a common problem in this population. Being relevant to know the etiology of the shoulder injury, based in the muscle imbalance and overuse by long concentration. However, coaches suggested change related to the application.

According to the experts' opinion, the home exercise program it is necessary for WB players. However, it is crucial to implement a systematic follow up of the home exercise program in the context of the training sessions. Some studies demonstrated that similar program that included stretching and strengthening exercise modified for the specific needs of the persons with SCI could be effective reducing shoulder pain (Curtis et al., 1999, Mulroy et al., 2011).

One physiotherapist $\mathrm{PH} 2$ considers "they are players with a much more developed musculature and that is why I do not consider that a specific exercise program is the most necessary" understanding that "must include relax massages for long training process would be the most useful". However, a few studies (Gutierrez, Thompson, Kemp, \& Mulroy, 2007) support the implementation of exercise program in the context of this population. Moreover, the coordinated action of the muscle around the glenohumeral joint is the principal in maintaining the joint integrity (Rozendaal, 1997). Related to the observation of the physiotherapist, the execution should be done considering the functional classification of the players, since the lower points (1.0-2.0) could lose stability when they do the exercises with both arms simultaneously for example, in the strengthening exercise for serratus anterior, scapular retractors and depressors and glenohumeral external rotation. However, in the study of Van Straaten, Cloud, Morrow, Ludewig, \& Zhao (2014) prescribed exercise with both arms considers that the sample included wheelchair users who had spinal cord injury at C6-7 level. In addition, it is needed to consider if players have shoulder pain, which explains the necessity of the individualization of an exercise program.

Experts evaluated the SHEP using 14 items that include clear and well defined objective, content organized per objective, the program is perceived as an important therapeutic tool, scientific bases, contains sufficient quantity and quality of information, contrasted and updated information, logical structure, clear and simple explanation, efficiently detailed structure, appropriate for therapeutic approach and relationship exercise, useful in relation to the object of study and its real applicability, easily reproducible, sequence of appropriate exercises and number of repetitions and adequate rest time (Table 2).

Quantitative analysis shows that the average obtained for the item refers to the scientific bases of the program were higher than the rest of the aspects evaluated; however, for the sequence of appropriate exercise a lower average of the answers was obtained (Table 2), this information had relationship with the suggestions of the expert in the qualitative analysis. 
A limitation of this study can be the number of experts who participated. However, we ensured that each participant has some relationship with the field of WB, and fulfilled the selected and demanding inclusion criteria. Future research should examine the effects home-based exercise program in $\mathrm{WB}$, in order to prevent shoulder pain and, also, to adapt this program in others wheelchair sports.

\section{Conclusion}

The current study provides evidence for adequate structure and content validity of the homebased exercise program as a valid tool and could be an option to prevent shoulder pain in wheelchair basketball players according to the opinion of the experts. However, it is necessary to determine its effectiveness in this specific population.

\section{Acknowledgments}

We would like to thank all the players who participated in the study and the FEDDF (Spanish Federation of Sports for Persons with Physical Disability).

\section{References}

Burnham, R. S., May, L., Nelson, E., Steadward, R., \& Reid, D. C. (1993). Shoulder pain in wheelchair athletes: the role of muscle imbalance. The American Journal of Sports Medicine, 21(2), 238-242.

Curtis, K. A., \& Dillon, D. A. (1985). Survey of wheelchair athletic injuries: common patterns and prevention. Spinal Cord, 23(3), 170-175.

Curtis, K. A., Tyner, T. M., Zachary, L., Lentell, G., Brink, D., Didyk, T. et al. (1999). Effect of a standard exercise protocol on shoulder pain in long-term wheelchair users. Spinal Cord, 37(6) 421-429.

Curtis, K. A., Roach, K. E., Applegate, E. B., Amar, T., Benbow, C. S., Genecco, T. D., \& Gualano, J. (1995). Reliability and validity of the wheelchair user's shoulder pain index (WUSPI). Paraplegia, 33(10), 595-601.

Finley, M. A. \& Rodgers, M. M. (2004) Prevalence and identification of shoulder pathology in athletic and nonathletic wheelchair users with shoulder pain: A pilot study. Journal of Rehabilitation Research and Development. 41(3B), 395-402.

Fullerton, H. D., Borckardt, J. J. \& Alfano, A. P. (2003). Shoulder pain: a comparison of wheelchair athletes and nonathletic wheelchair users. Journal of Medicine Science Sports Exercise, 35(12), 1958-1961.

Gutierrez, D. D., Thompson, L., Kemp, B., \& Mulroy, S. J. (2007). The relationship of shoulder pain intensity to quality of life, physical activity, and community participation in persons with paraplegia. The Journal of Spinal Cord Medicine, 30(3), 251-255.

Heinemann, K. (Ed.). (2003). Introducción a la metodología de la investigación empírica en las ciencias del deporte. Barcelona: Paidotribo.

Jacobs, P. L., Mahoney, E. T., Nash, M. S., \& Green, B. A. (2002). Circuit resistance training in persons with complete paraplegia. Journal of Rehabilitation Research and Development, 39(1), 21. 
Killian, M. L., Cavinatto, L., Galatz, M. L. \& Thomopoulos, S. (2012). Recent advances in shoulder research. Arthritis Research \& Therapy 14, 214.

Nash, M. S., van de Ven, I., van Elk, N. \& Johnson, B. M. (2007). Effects of circuit resistance training on fitness attributes and upper-extremity pain in middle-aged men with paraplegia. Archives of Physical Medicine and Rehabilitation, 88(1), 70-75.

Nawoczenski, D. A., Ritter-Soronen, J. M., Wilson, C. M., Howe, B. A., \& Ludewig, P. M. (2006). Clinical trial of exercise for shoulder pain in chronic spinal injury. Physical Therapy, 86(12), 1604-1618.

Morrow, J. R., Jackson, A. W., Disch, J. G., \& Mood, D. P. (2005). Measurement and Evaluation in Human Performance. Champaign, IL: Human Kinetics.

Mulroy, S. J., Thompson, L., Kemp, B., Hatchett, P. P., Newsam, C. J., Lupold, D. G., \& Winstein, C. J. (2011). Strengthening and optimal movements for painful shoulders (STOMPS) in chronic spinal cord injury: a randomized controlled trial. Physical Therapy.

Rozendaal, L. A. (Ed.). (1997). Stability of the shoulder: intrinsic muscle properties and reflexive control. The Netherlands: NWO-NW Netherlands Organizations for Scientific Research- medical Sciences.

Samuelsson. K. A., Tropp, H., \& Gerdle, B. (2004) Shoulder pain and its consequences in paraplegic spinal cord-injured, wheelchair users. Spinal Cord, 42(1), 41-46.

Tsunoda, K., Mutsuzaki, H., Hotta, K., Tachibana, K., Shimizu, Y., Fukaya, T., ... \& Wadano, Y. (2016). Correlates of shoulder pain in wheelchair basketball players from the Japanese national team: A cross-sectional study. Journal of Back and Musculoskeletal Rehabilitation, (Preprint), 1-6.

Van Straaten MG, Cloud, B. A., Morrow, M. M., Ludewig, P. M., \& Zhao, K. D. (2014). Effectiveness of Home Exercise on Pain, Function, and Strength of Manual Wheelchair Users With Spinal Cord Injury: A High-Dose Shoulder Program With Telerehabilitation. Archive of Physical Medicine and Rehabilitation, 95:1810-1817.

Wessels, Kg. K., Brown, J. L., Ebersole, K. T. \& Sosnoff, J. J. (2013). Sex, shoulder pain, and range of motion in manual wheelchair users. Journal of Rehabilitation Research and Development, 50(3), 351-356.

Yoo, J. S., Hwang, A. R., Leez, H. C., \& Kim, C. J. (2003). Development and Validation of a Computerized Exercise Intervention Program for Patients with Type 2 Diabetes. Yonsei Medical Journal, 44(5), 892-904. 